\title{
Finite element analysis of flexural behavior of a new rectangular hollow flange beam (NRHFB)
}

\author{
Li Wang ${ }^{1, a}$, Yongbo Shao ${ }^{2, b^{*}}$ and Yamin Wang ${ }^{2, c}$ \\ ${ }^{1}$ School of Civil Engineering, Yantai University, Yantai, China \\ ${ }^{2}$ School of Mechatronic Engineering, Southwest Petroleum University, Chengdu, China \\ aemail: heeryang@163.com, bemail: ybshao@swpu.edu.cn, cemail: wangyamin1215@163.com
}

Keywords: New rectangular hollow flange beam (NRHFB), flexural behavior, finite element analysis. Abstract. This study presents a new rectangular hollow flange beam (NRHFB). In this new beam, the top flange is designed to be rectangular hollow section. Considering a thin-wall hollow section flange is much weaker in resisting concentrated load, the web is penetrating through the tubular flange to sustain local concentrated load. Using finite element analysis, the flexural behavior of the new beam is compared with conventional I-beam and hollow flange beam. The comparison indicates that NRHFB is more advantageous in resisting loccal concentrated load.

\section{Introduction}

I-shape beam is widely used in building structures, and it is consisted of two flanges and a web. Both the flanges and the web are generally designed to be flat plate. This conventional beam is sensitive to global buckling when the height of the beam is bigger because the cross section is an open-section which is weak in torsional resistance. To improve the resistance to global buckling, the compressed flange of a beam is designed to be tubular because the cross section of a tube is closed.

In the past three decades, many research studies in I-beams with tubular flange have been conducted ([1]-[9]), and the results show that the tubular flange in a beam can improve the torsional deformation efficiently. However, the weak transverse stiffness of the tube causes the beam to have a low capacity to resist the local concentrated load. This study aims to present a new tubular flange beam, which improves the resistance to concentrated load by web penetrated into the tubular flange.

\section{New rectangular hollow flange beam (NRHFB)}

The presented new rectangular hollow flange beam (NRHFB) is illustrated in Fig. 1. Compared to conventional I-girder and the hollow flange beam LHFB, NRHFB is much similar to LHFB except the web. In NRHFB, the web penetrates the top hollow tubular flange, and it contacts with the top surface of the tubular flange. The penetrated web is used to resist local concentrated load.

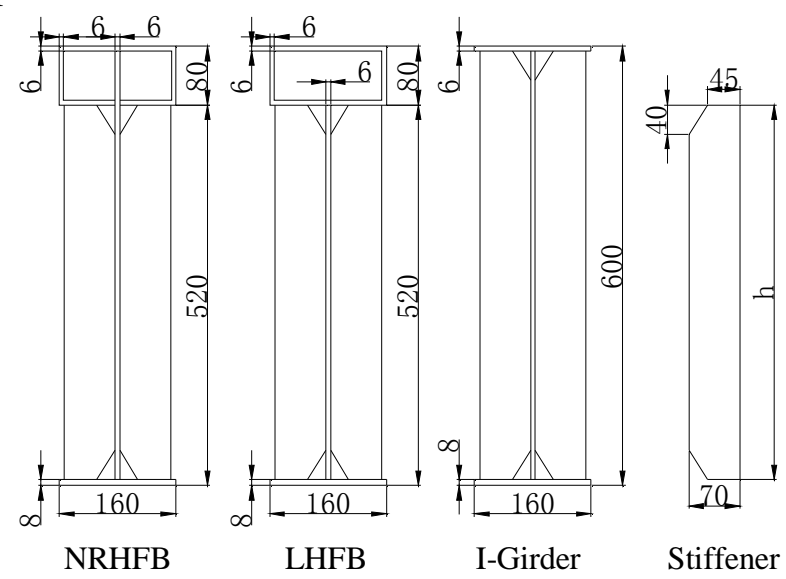

Fig. 1 Different I-shape beams 


\section{Finite element analysis}

To investigate the performance of NRHFB, finite element analysis is carried out. NRHFB, LHFB and I-girder are all simulated, and the dimensions of the three beams are shown in Fig. 1. The steel plates used to fabricate the beams include two thickness values: $6 \mathrm{~mm}$ and $8 \mathrm{~mm}$. For the steel plates with a thickness of $6 \mathrm{~mm}$, the yield strength is $280 \mathrm{MPa}$. For the steel plates with a thickness of $8 \mathrm{~mm}$, the yield strength is $252 \mathrm{MPa}$. The elastic modulus of all the steel plates is $206 \mathrm{GPa}$.

In the mesh of the beams, shell elements are used. All the beams are hinged at two ends. The lengths of the three beams are all $6000 \mathrm{~mm}$. A concentrated load is applied at the mid-span, and the loading area is illustrated in Fig. 2. The concentrated load is simulated as a local pressure in the marked region in Fig. 2. The detailed mesh of NRHFB is shown in Fig. 3.

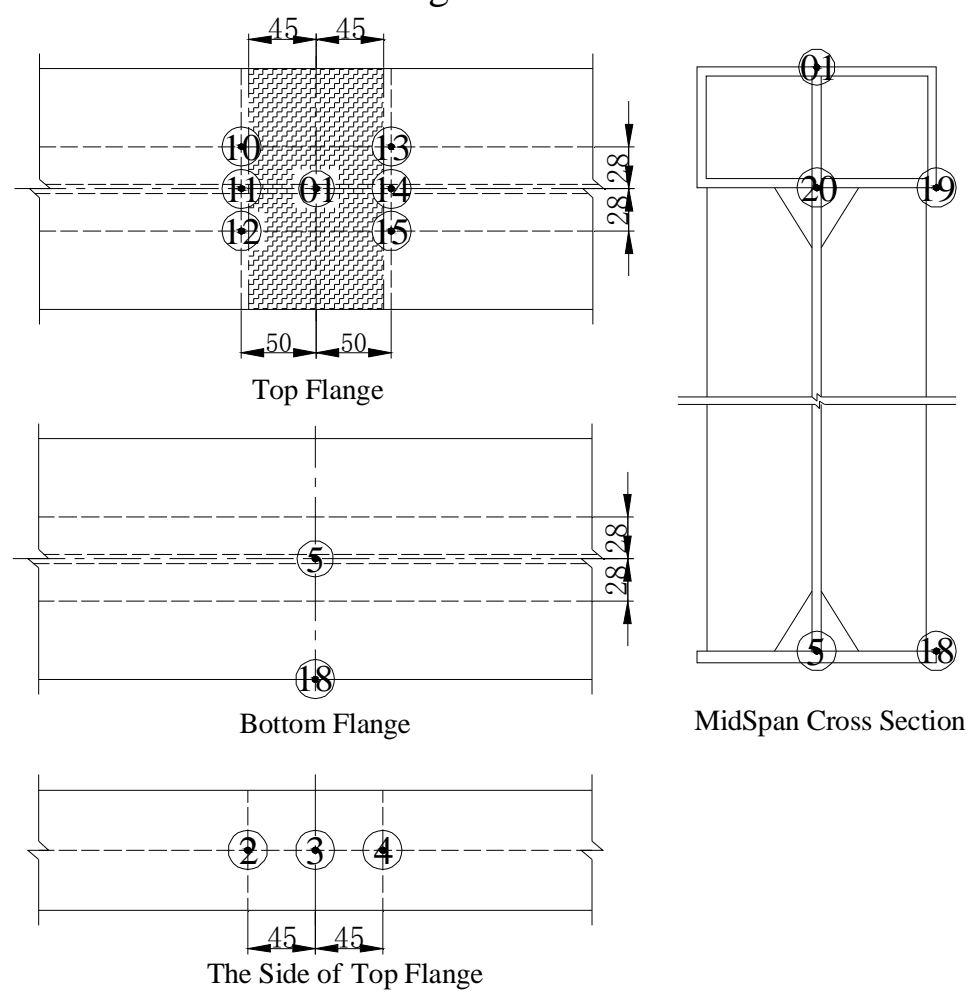

Fig. 2 Loading area in the beam

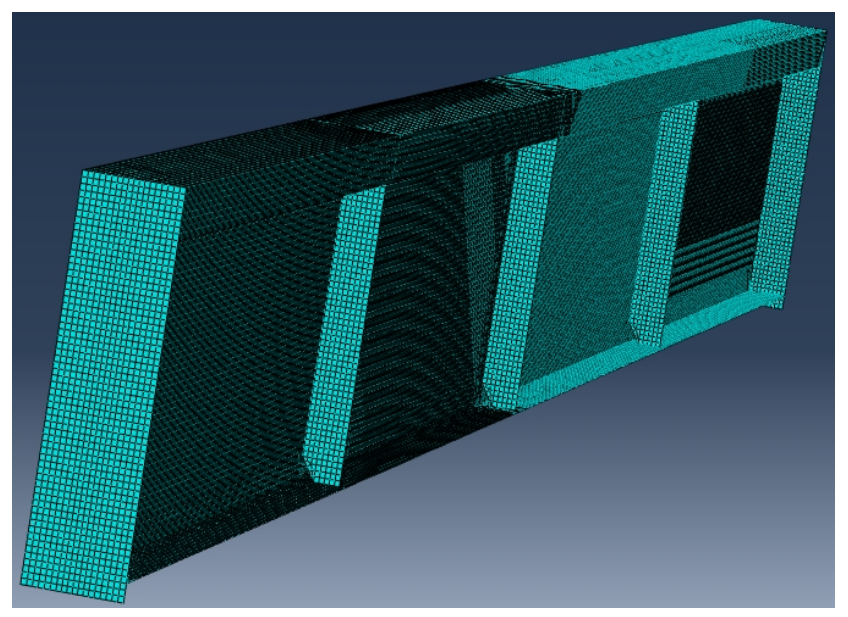

Fig. 3 The Mesh of NRHFB

Using finite element analysis, the load-deflection curves of the three beams are obtained and plotted together in Fig. 4. It is found from the finite element results that flat plate I-girder has a lowest load carrying capacity compared to the hollow tubular flange beams. Especially after the peak value, the load reduces continuously, which implies that the beam fails suddenly without any potential to resist external loading any more. 


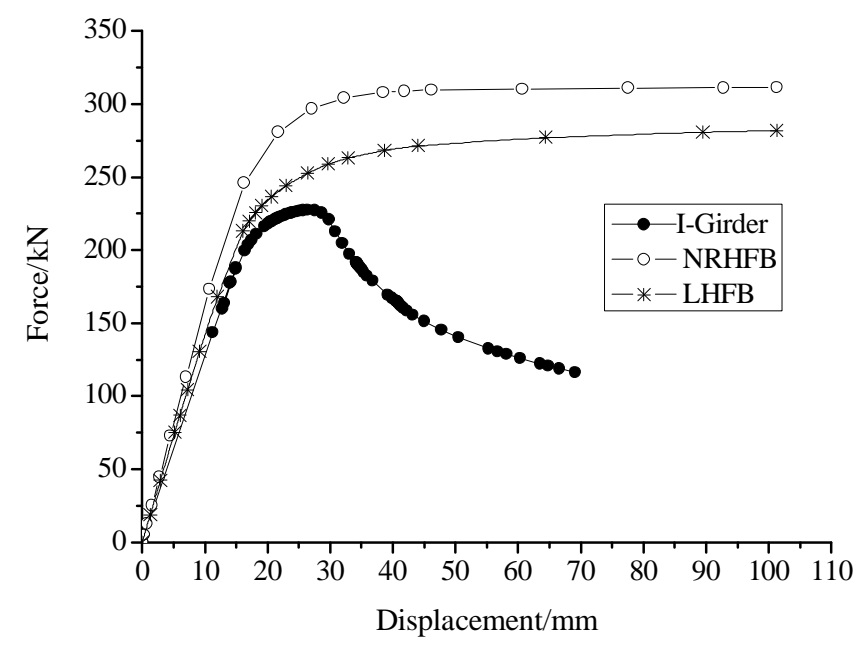

Fig. 4 Load-deflection curves of three beams

For the hollow flange beams, however, the load has no clear peak value, and only a knee point exists in the curves. After the knee point, the load increase very gradually. However, the load does not reduce. This phenomenon occurs due to the different failure modes. For I-girder with flat plates, its final failure mode is global buckling while no global buckling occurs in the other two hollow tubular flange beams. Since strength rather than global buckling is dominant in the two hollow tubular flange beams, the load carrying capacities of I-girder, LHFB and NRHFB are $188 \mathrm{kN}, 281 \mathrm{kN}$ and $311 \mathrm{kN}$ respectively. LHFB and NRHFB have an increase of the load carrying capacity of $49.5 \%$ and $65.4 \%$ respectively.

Although both LHFB and NRHFB can improve the flexural strength of conventional flat plate I-girders, the failure modes of the two beams are also different. Fig. 5 shows the cross sections of the two beams at the mid-span. Clearly, the LHFB has a remarkable deformation in the top tubular flange. However, such local deformation of the tubular flange is much smaller for the NRHFB since the penetrated web can sustain the concentrated load at the mid-span.
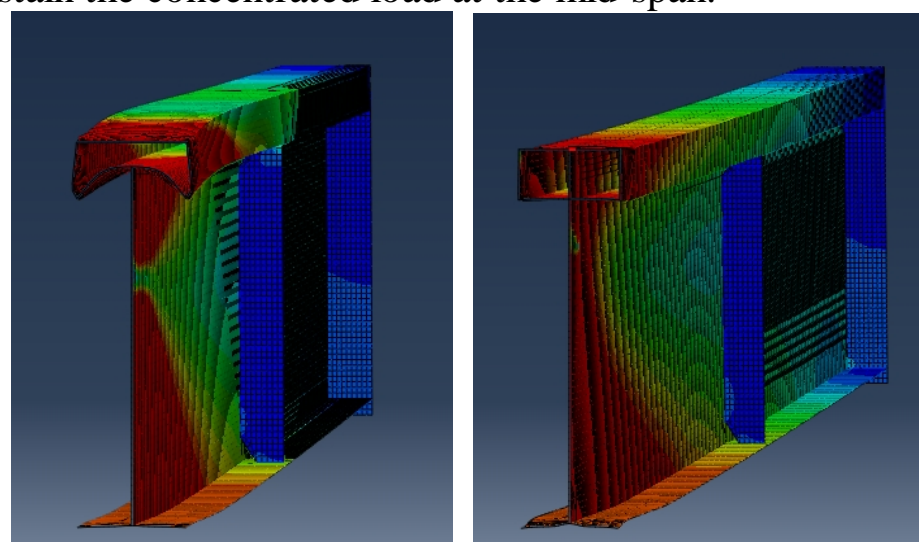

Fig. 5 Deformation of the top tubular flange

If the local deformation of the top tubular flange is evaluated from the displacements at points 10 and 11, the deformation developments of LHFB and NRHFB are illustrated in Fig. 6. Obviously, the maximum deformation of the top tubular flange for LHFB is about $22.3 \mathrm{~mm}$. However, such deformation varies very slightly during the whole loading process for NRHFB, and the maximum deformations at points 10 and 11 are $0.152 \mathrm{~mm}$ and $0.353 \mathrm{~mm}$ respectively. The results indicate that the penetrated web in the NRHFB can sustain the concentrated load at the mid-span efficiently, which can reduce the local deformation of the tubular flange remarkably. 


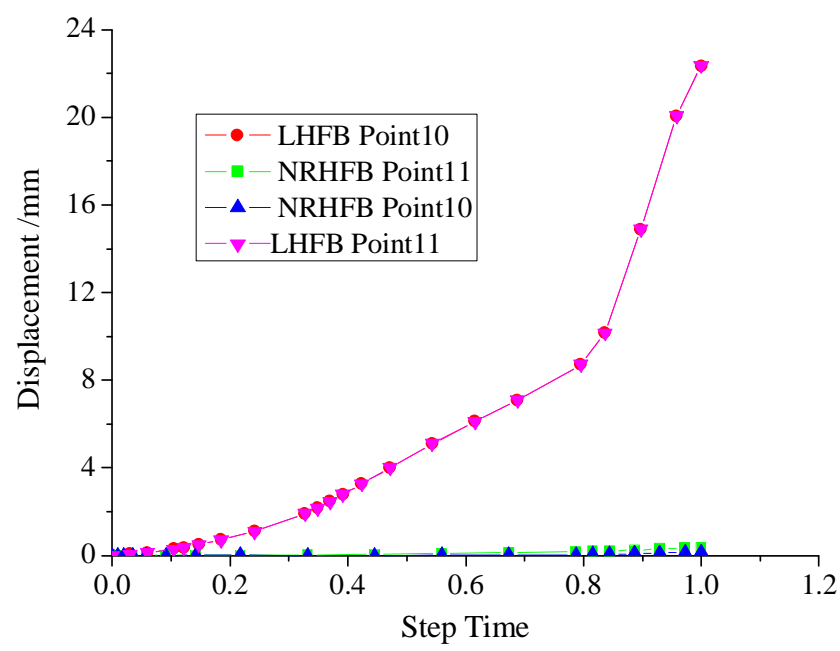

Fig. 6 Deformation development of the tubular flange

\section{Conclusions}

Through finite element analysis for the flexural behavior of three different beams, the following three conclusions can be drawn: (1) tubular flange can improve the torsional stiffness, and thus it can increase the resistance of a beam to global buckling failure; (2) by penetrating the web into the tubular flange, the web can resist local concentrated load efficiently, and thus to decrease the deformation of the tubular flange; (3) hollow tubular flange can improve the load carrying capacity efficiently.

\section{References}

[1] P. Avery, M. Mahendran, A. Nasir. J. Constr. Steel Res. Vol. 23 (2000), p. 201.

[2] P. Avery, M. Mahendran. J. Struct. Engrg. Vol. 123(1997), p. 1130.

[3] P. Avery, M. Mahendran. J. Struct. Engrg. Vol. 123(1997), p. 1123.

[4] J. Dong, R. Sause. J. Constr. Steel Res. Vol. 65(2009), p. 622.

[5] M.F. Hassanein, O.F. Kharoob. Thin-Walled Struct. Vol. 69(2013), p. 18.

[6]. M.F. Hassanein, N. Silvestre. Engrg. Struct. Vol. 56(2013), p. 572.

[7] A. Mohebkhah, M.G. Azandarian. Thin-Walled Struct. Vol. 86(2015), p. 167-173.

[8] Y.L. Pi, N.S. Trahair. J. Struct. Engrg. Vol. 123(1997), p. 695. 